\title{
Simulation and prediction of urban heat island effect of urban high-speed rail construction
}

\author{
Hong Jiao, Yachun Fang* \\ Northeast Forestry University, Urban and Rural Planning Design Research Center, Harbin 150040, China
}

Corresponding Author Email: fangyachun0614@163.com

https://doi.org/10.18280/ijht.360436

Received: 8 April 2018

Accepted: 28 August 2018

Keywords:
urban heat island (UHI) effect, high-
speed rail (HSR) construction,
urbanization; surface temperature,
population, greyscale theory

Keywords:

urban heat island (UHI) effect, hightemperature, population, greyscale theory

\begin{abstract}
This paper aims to disclose the impact of urban high-speed rail (HSR) construction on the urban heat island (UHI) effect and predict the UHI effect in future. For this purpose, the radiation transmission method was adopted to investigate the UHI effect in south-eastern China's Nanchang city, and forecasted the UHI effect from 2018 to 2025 in Nanchang via longitudinal greyscale simulation. The research results show that: the surface temperature is closely related to the urban HSR construction; the maximum surface temperature increases with the built-up area of the HSR; different factors have different effects on the UHI effect, among which population is the leading influencing factor; the mean temperature in 2018 2025 indicates the HSR construction in Nanchang has a severe HSR effect. The research finding shed new light on the studies of UHI effect and its influencing factors.
\end{abstract}

\section{INTRODUCTION}

Rapid urbanization is a global phenomenon that contributes to climate warming, and promotes the awareness of the significance of urban thermal environment [1]. With the accelerating expansion and development of cities, more and more energies are consumed by the growing urban population. The resulting growth in heat emissions has led to marked urban heat island (UHI) effect in many fast-developing countries, causing severe environmental problems [3-4]. The UHI is an urban area that is significantly warmer than its surrounding rural areas, due to the expansion of urban population, the high density of buildings, as well as the numerous energy sources and pollutants [2]. The UHI effect directly bears on the microclimate in cities, and easily brings environmental problems and extreme weather. Besides, this effect has a severe negative impact on human health, as the future climate temperature is expected to increase rapidly with the urban population [9]. Thus, it is necessary to carry out scientific and effective research into urban surface temperature and the formation law of the UHI effect, laying the basis for rational urban planning and heathy urban development [5].

Currently, the UHI effect is being exacerbated by the construction of high-speed rail (HSR) in cities. This construction process has attracted intensive flow of people and propelled rapid economic growth. As a result, the heat emissions continue to rise in cities, pushing up the urban temperature $[14,8]$. The stimulation of the UHI effect by HSR construction should not be neglected, although the HSR can improve time accessibility between cities, enhance urban connectivity, boost the flow of production factors and motivate regional development [6].

The UHI effect is often calculated by the thermal infrared inversion of surface temperature. The relevant algorithms mainly fall into specific radiance model, two-parameter model, complex model and simple model [10]. For instance, the splitwindow algorithm divides the same atmospheric window into two adjacent thermal infrared bands for observation. The multi-angle algorithm assumes that a target has different atmospheric absorption rate of surface radiation from different observation angles when the atmosphere is uniform. With the development of remote sensing technology, remote sensing bands can be used to determine urban geothermal temperatures, laying the basis for inversion and detection of urban thermal environments $[11,12]$.

Considering the above, this paper investigates the UHI effect using the radiation transmission method, aiming to disclose the impact of urban HSR construction on the UHI effect and predict the UHI effect in future.

\section{RELEVANT THEORIES}

\subsection{Theories and methods of surface temperature inversion}

Materials differ in thermal radiation because of the difference in surface morphology and internal composition. In light of this, the thermal infrared remote sensing collects, records and identifies thermal infrared information by satellite or airborne sensors [13]. Kirchhoff's law and Planck's law are leading theories on thermal infrared remote sensing [14].

By the type of sensor, surface temperature inversion algorithms can be divided into single-channel algorithm, multi-channel algorithm and split-window algorithm. Among them, the sing-window algorithm stands out for its high accuracy $(0.2 \mathrm{~K})$ through the computation based on atmospheric transmittance, mean temperature of atmospheric action and surface specific radiance rate [15]. The singlewindow algorithm can be expressed as:

$$
\begin{aligned}
& \mathrm{T}_{\mathrm{s}}=[\mathrm{a}(1-\mathrm{C}-\mathrm{D})+(\mathrm{b}(1-\mathrm{C}-\mathrm{D})+\mathrm{C}+\mathrm{D}) \mathrm{T}-\mathrm{DT}] / \mathrm{C} \\
& \mathrm{C}=\varepsilon \tau \\
& \mathrm{D}=(1-\varepsilon)[1+(1-\varepsilon) \tau]
\end{aligned}
$$


where $T_{s}$ is the surface temperature; $T$ is the brightness temperature acquired via remote sensing; $a$ and $b$ are constants; $\mathrm{C}$ and $\mathrm{D}$ are intermediate variables; $\varepsilon$ is the surface specific emissivity; $\tau$ is the atmospheric infrared transmittance in the thermal infrared band.

\subsection{Theories on remote sensing images}

Remote sensing images can be classified according to spectral and ground-object features. Spectral features generally refer to the pixel greyscale of ground-object image, while ground-object features include distribution and texture attributes [16]. The two popular classification methods are manual visual interpretation and computer automatic classification. The former is prone to subjective bias, while the latter can automatically extract feature data for category judgment [17]. Computer automatic classification is further divided into supervised classification and unsupervised classification. The common approaches of supervised classification cover minimum distance method, maximum likelihood method, support vector machine classification and backpropagation (BP) neural network classification.

\section{UHI EFFECT OF URBAN HSR CONSTRUCTION}

\subsection{Spatiotemporal features of thermal environment}

The UHI effect is influenced by the urbanization process, especially the land utilization and the change of land type. The processing of remote sensing images involves such step as radiometric calibration, geometric correction, atmospheric correction, image mosaicking and cropping. Different image data may lead to different inversion results of surface temperature. Here, the remote sensing radiance is converted into surface temperature by the Plank function:

$\mathrm{Ts}=\mathrm{K}_{2} / \ln \left(\mathrm{K}_{1} / \mathrm{B}(\mathrm{Ts})+1\right)-273.15$

where $\mathrm{K}_{1}$ and $\mathrm{K}_{2}$ are constants. The parameters affecting the thermal infrared bands are list in Table 1 below.

Table 1. Parameters affecting the thermal infrared bands

\begin{tabular}{ccc}
\hline Parameters & Landsat5/TM & Landsat 8 \\
\hline $\mathrm{K}_{1} /\left(\mathrm{w} \cdot \mathrm{m}^{-2} \cdot \mathrm{sr}^{-1} \cdot \mathrm{um}^{-1}\right)$ & 616.85 & 783.98 \\
$\mathrm{~K}_{2} / \mathrm{K}$ & 1269.65 & 1330.17 \\
\hline
\end{tabular}

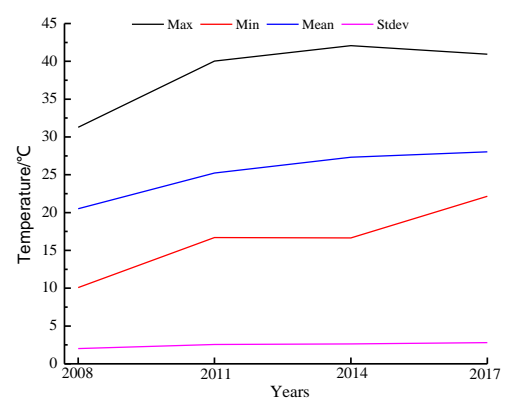

Figure 1. Surface temperature in Nanchang (2008 2017)

Figure 1 presents the surface temperature of south-eastern China's Nanchang city from 2008 to 2017. It is obvious that the maximum, mean and standard deviation of the surface temperature were all increasing from 2008 to 2014. From 2014 to 2017 , the maximum surface temperature decreased, but the minimum surface temperature and standard deviation were still on the rise. Then, the UHI level was divided according to the inversion results on surface temperature. The normalization formula can be expressed as:

$\operatorname{Tg}=\left(\mathrm{t}-\mathrm{t}_{\min }\right) /\left(\mathrm{t}_{\max }-\mathrm{t}_{\min }\right)$

where $t, t_{\min }$ and $t_{\max }$ are the absolute, the minimum and the maximum pixel temperature, respectively. By equation (4), the UHI was divided into six levels: $0-0.5,0.5-0.6,0.6-0.7,0.7-$ $0.8,0.8-0.9$ and $0.9-1.0$. The $\mathrm{Tg}$ value is negatively correlated with the surface temperature. Table 2 shows the area of each UHI level in Nanchang (Level 1 has the highest temperature). It can be seen that the higher the level, the larger the UHI area.

Table 2. The area of each UHI level in Nanchang $/ \mathrm{km}^{2}$

\begin{tabular}{ccccc}
\hline Number & 2008 & 2011 & 2014 & 2017 \\
\hline 1 & 1507.31 & 1495.94 & 1400.67 & 1377.93 \\
2 & 1052.68 & 1260.25 & 1159.50 & 1195.86 \\
3 & 1196.13 & 1048.67 & 1220.51 & 1236.48 \\
4 & 1196.31 & 1299.14 & 1202.78 & 1136.24 \\
5 & 1195.05 & 1059.49 & 1169.17 & 1205.74 \\
6 & 1193.71 & 1177.74 & 1188.61 & 1189.03 \\
\hline
\end{tabular}

\subsection{Relationship between surface temperature and surface indices}

Table 3 introduces the urban green space classification system. As shown in the table, the urban surface is classified into vegetation, bare land, construction land and water area. The area of each type of land use in 2008, 2011, 2014 and 2017 is summed up in Figure 2. It can be seen that, over the ten years, the vegetation gradually shrank, the construction land increased, and the construction land septupled. The fast growth in construction land is attributable to the HSR construction. The four surface types were combined with the maximum, minimum, mean and standard deviation of surface temperature to determine the relationship between the surface type and surface indices. Table 4 displays the surface temperature of each type of land use in 2017 . The normalized surface indices can be expressed as:

Normalized difference vegetation index: $\mathrm{NDVI}=(\mathrm{NIR}-$ Red)/(NIR+Red) (5)

Normalized difference water index: NDWI $=($ Green-NIR $) /$ (Green+NIR) (6)

Normalized difference building Index: NDBI $=(\mathrm{MIR}-$ NIR)/(MIR+NIR) (8)

Table 3. Urban green space classification system

\begin{tabular}{|c|c|c|}
\hline $\begin{array}{l}\text { Land } \\
\text { number }\end{array}$ & Land name & Meaning \\
\hline 1 & Vegetation & $\begin{array}{c}\text { Green vegetation cover in forest land, } \\
\text { greening, grassland, cultivated land, } \\
\text { etc. }\end{array}$ \\
\hline 2 & Bare land & $\begin{array}{l}\text { Natural bare land, developing bare } \\
\text { land and river beach sand }\end{array}$ \\
\hline 3 & $\begin{array}{l}\text { Building } \\
\text { land }\end{array}$ & $\begin{array}{l}\text { Urban construction land, urban } \\
\text { residents and traffic construction land }\end{array}$ \\
\hline 4 & Waters & $\begin{array}{c}\text { Rivers, lakes, reservoirs, pits and } \\
\text { waters }\end{array}$ \\
\hline
\end{tabular}


where NIR is the near-infrared band; Red is the red band; Green is the green band; MIR is the mid-infrared band.

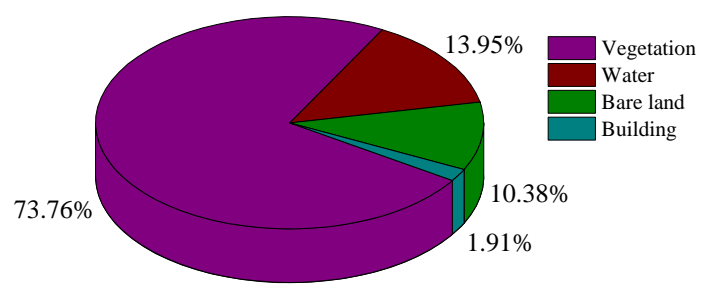

(a) 2008

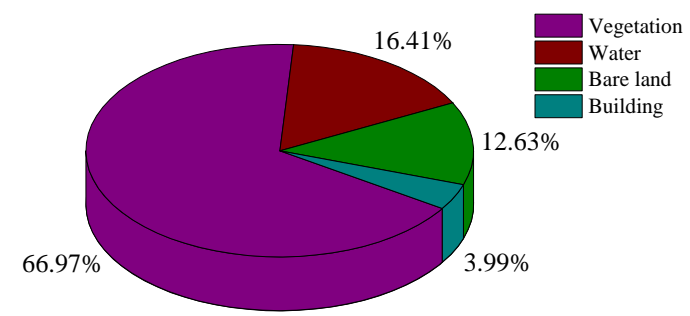

(b) 2011

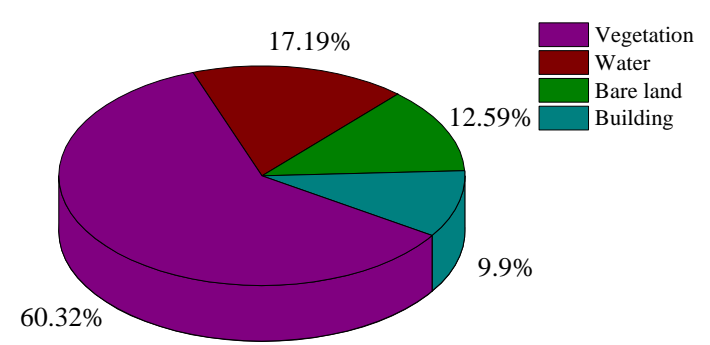

(c) 2014

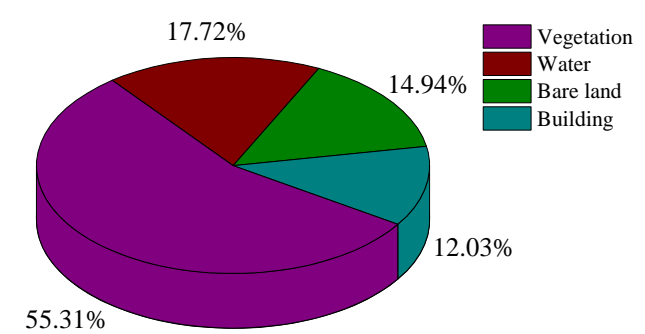

(d) 2017

Figure 2. The area of each type of land use in 2008, 2011, 2014 and 2017

Table 4. The surface temperature of each type of land use in 2017

\begin{tabular}{ccccc}
\hline & Minimum & Maximum & $\begin{array}{c}\text { Average } \\
\text { value }\end{array}$ & $\begin{array}{c}\text { Standard } \\
\text { deviation }\end{array}$ \\
\hline Vegetation & 17.1232 & 38.6825 & 25.9918 & 1.6964 \\
Water & 21.2638 & 37.4621 & 24.3655 & 1.4627 \\
Bare land & 29.7211 & 40.9648 & 29.2449 & 2.1427 \\
Building & 30.7615 & 41.7819 & 30.8491 & 2.2453 \\
\hline
\end{tabular}

Next, the relationships between surface temperature and the NDVI, NDWI and NDBI were ascertained and plotted as Figures 3 5. Obviously, the surface temperature is negatively correlated with the NDVI and NDWI, and positively with the NDBI.

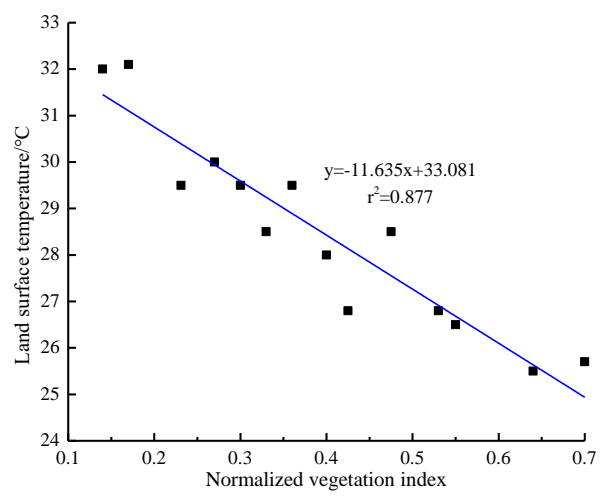

Figure 3. Relationship between surface temperature and the NDVI

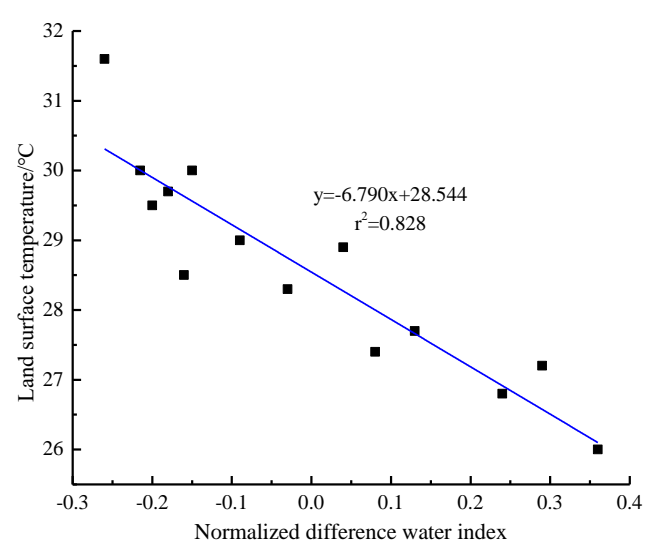

Figure 4. Relationship between surface temperature and the NDWI

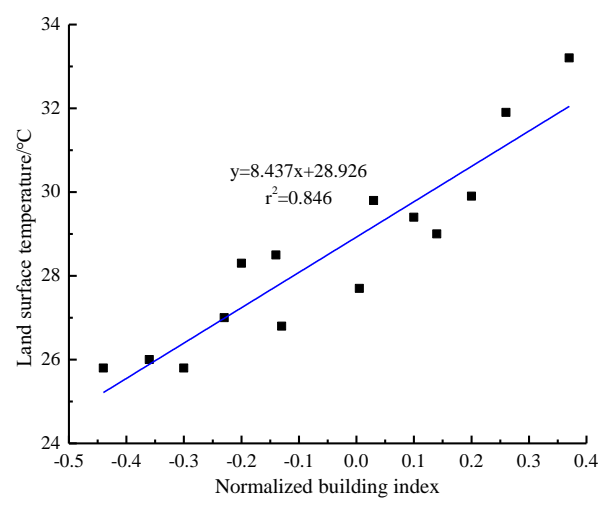

Figure 5. Relationship between surface temperature and the NBVI

\section{FACTORS IMPACTING UHI EFFECT OF URBAN HSR CONSTRUCTION AND PREDICTION MODEL}

\subsection{Quantitative study of the factors impacting the UHI effect}

Table 5 shows the HSR built-up area and the green area in Nanchang. It is clear that the HSR built-up area in Nanchang increased steadily in recent years. The UHI effect is a very complex system in urban development, and the most prominent problem in urban environment. The HSR construction promotes the generation of the UHI effect through its impacts on various factors, namely, urban 
expansion, urban underlying surfaces and industrial energy consumption.

Table 5. the HSR built-up area and the green area in Nanchang

\begin{tabular}{ccc}
\hline Years & High-speed railway built-up area $/ \mathrm{km}^{2}$ & Green area $/ \mathrm{km}^{2}$ \\
\hline 2012 & 2.015 & 21.41 \\
2013 & 2.080 & 22.09 \\
2014 & 2.150 & 23.20 \\
2015 & 2.495 & 23.60 \\
2016 & 2.620 & 24.17 \\
2017 & 3.073 & 29.61 \\
\hline
\end{tabular}

Table 6 presents the changes of the said factors in Nanchang from 2012 to 2017, including precipitation, urban population, gross industrial output and anthropogenic heat emissions. Each factor was assigned a greyscale according to the greyscale theory. The annual mean temperature was taken as the metavariable, and the factors in Table 6 as independent variables. Based on the grey relational analysis, the system characteristic behaviour sequence was configured to derive the greyscale correlation between each factor and the annual mean temperature.

Table 6. The changes of various factors in Nanchang from 2012 to 2017

\begin{tabular}{ccccc}
\hline $\begin{array}{c}\text { Urban } \\
\text { S }\end{array}$ & Rainfall/mm & $\begin{array}{c}\text { population } \\
\text { /Ten } \\
\text { thousand } \\
\text { people }\end{array}$ & $\begin{array}{c}\text { Industrial } \\
\text { value } \\
\text { /Billion }\end{array}$ & $\begin{array}{c}\text { Anthropogeni } \\
\text { c heat } \\
\text { emissions }\end{array}$ \\
\hline 2012 & 2122.2 & 211.34 & 94.164 & 2295.40 \\
2013 & 1019.5 & 214.5 & 114.400 & 5649.54 \\
2014 & 1948.7 & 224.12 & 127.982 & 11139.21 \\
2015 & 1342.7 & 232.63 & 138.752 & 15933.32 \\
2016 & 1801.6 & 236.35 & 148.960 & 19781.36 \\
2017 & 2115.8 & 250.73 & 160.840 & 23808.12 \\
\hline
\end{tabular}

\subsection{Construction of UHI effect prediction model}

Construction land is the main driving factor for urban surface warming. Figure 6 gives the seasonal composition of surface temperature for construction land from 2012 to 2017. Figure 7 shows the observed surface temperature and trend in the same period. It can be seen that the surface temperature of construction land fluctuated greatly, and increased at an annual rate of $1.63^{\circ} \mathrm{C}$ from 2012 to 2017 . Based on the quantitative results in the previous section, the author predicted the UHI effect via longitudinal greyscale simulation, which is a quantitative analysis method for the degree of influence between factors or the contribution of factors to the main behaviour according to the dynamic development trend of the system. The prediction shows, as the minimum temperature was recorded in $2012\left(18.051^{\circ} \mathrm{C}\right)$, the minimum temperature will appear in $2021\left(18.342^{\circ} \mathrm{C}\right)$ for the period between 2018 and 2015 and will change slightly in the following four years. Figure 8 shows the predicted annual mean temperature for 2012 2025. Considering the temperature change in Nanchang over the past three decades, it is predicted that the annual mean temperature from 2012 to 2025 will be higher than that of the past, indicating that the HSR construction will bring a strong UHI effect to Nanchang.

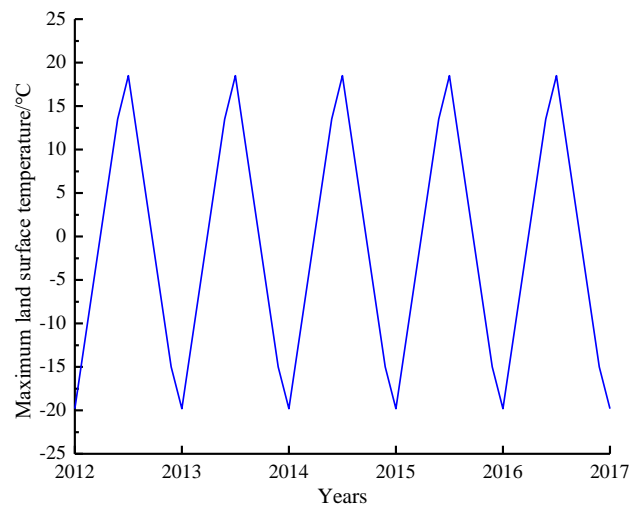

Figure 6. Seasonal composition of surface temperature for construction land from 2012 to 2017

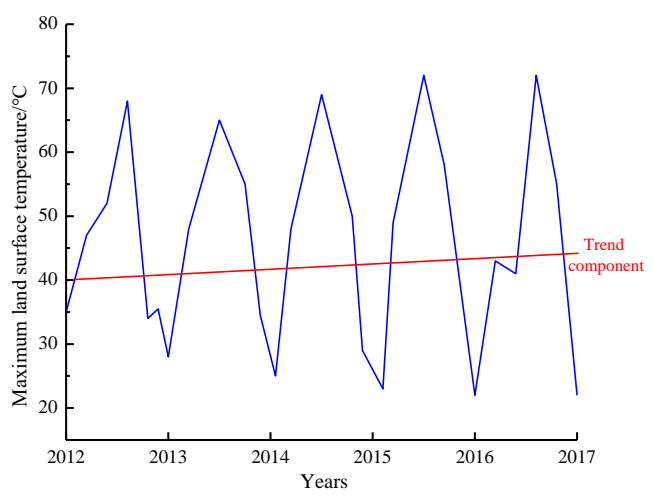

Figure 7. Observed surface temperature and trend from 2012 to 2017

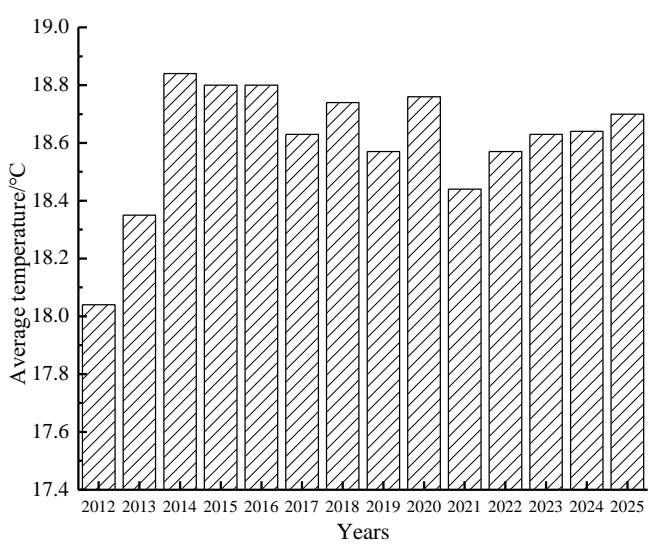

Figure 8. Predicted annual mean temperature for 2012 2025

\subsection{Mitigation measures for the UHI effect}

The UHI effect is enhanced by the HSR construction, as the latter can boost urban population mobility, anthropogenic heat emissions, urbanization speed and construction land use. To alleviate the UHI effect, the government should rationally plan the area and layout of different types of land uses according to the local conditions, the urban development plan and the urban arrangement. Moreover, the ventilation gaps between buildings and roads should be maintained to increase heat emissions and reduce surface heat. Another important measure is to strengthen urban ecological construction. Vegetation can absorb suspended matters in the air through photosynthesis, and thus reduce light refraction. Vegetation, especially that near buildings, and water area are negatively correlated with 
urban surface temperature. Thus, more artificial lakes should be built to curb the UHI effect through the heat absorption in water evaporation. In addition, green technology and lowcarbon travel should be encouraged to reduce the anthropogenic heat released by the growing urban population.

\section{CONCLUSIONS}

This paper investigates the impact of urban HSR construction on the UHI effect and predicts the UHI effect in future. The main conclusions are as follows:

(1) Concerning the surface temperature in Nanchang, the maximum, mean and standard deviation of the surface temperature were all increasing from 2008 to 2014. From 2014 to 2017 , the maximum surface temperature decreased, but the minimum surface temperature and standard deviation were still on the rise.

(2) After studying the type of land use and surface temperature, it is learned that, over the past ten years, the vegetation gradually shrank, the construction land increased, and the construction land septupled. The fast growth in construction land is attributable to the HSR construction. Besides, the surface temperature is negatively correlated with the NDVI and NDWI, and positively with the NDBI.

(3) The HSR construction has boosted urban expansion, changed urban underlying surfaces and pushed up industrial energy consumption. As a result, the surface temperature of construction land in Nanchang increased at an annual rate of $1.63^{\circ} \mathrm{C}$ from 2012 to 2017 . It can be judged that the HSR construction in Nanchang has a severe HSR effect.

\section{REFERENCES}

[1] Gagliano A, Nocera F, Aneli S. (2017). Computational fluid dynamics analysis for evaluating the urban heat island effects. Energy Procedia 134: 508-517. http://doi.org/10.1016/j.egypro.2017.09.557

[2] Cannistraro G, Cannistraro M, Cao J, Ponterio L. (2018). New technique monitoring and transmission environmental data with mobile systems. Instrumentation, Mesure, Métrologie 17(4): 549-562, http://dx.doi.org/10.3166/I2M.17.549-562

[3] Mathew A, Khandelwal S, Kaul N. (2018). Analysis of diurnal surface temperature variations for the assessment of surface urban heat island effect over Indian cities. Energy Buildings 159: 271-295. http://doi.org/10.1016/j.enbuild.2017.10.062

[4] Zhang Y, Wang Z, Sun Y. (2009). Analysis of urban heat island effect using an improved cttc and sttc model. Transactions of Tianjin University 15(3): 201-205. http://doi.org/10.1007/s12209-009-0035-0

[5] Pal S, Xueref-Remy I, Ammoura L, Chazette P, Gibert F, Royer P. (2012). Spatio-temporal variability of the atmospheric boundary layer depth over the Paris agglomeration: an assessment of the impact of the urban heat island intensity. Atmospheric Environment 63(15): 261-275. http://doi.org/10.1016/j.atmosenv.2012.09.046

[6] Theophilou MK, Serghides D. (2015). Estimating the characteristics of the urban heat island effect in Nicosia, Cyprus, using multiyear urban and rural climatic data and analysis. Energy \& Buildings 108: 137-144. http://doi.org/10.1016/j.enbuild.2015.08.034

[7] Bonafoni S, Baldinelli G, Verducci P. (2017). Sustainable strategies for smart cities: analysis of the town development effect on surface urban heat island through remote sensing methodologies. Sustainable

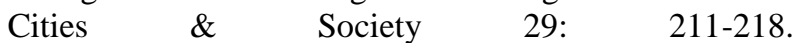
http://doi.org/10.1016/j.scs.2016.11.005

[8] Memon RA, Leung DYC, Liu CH, Leung MKH. (2011). Urban heat island and its effect on the cooling and heating demands in urban and suburban areas of Hong Kong. Theoretical \& Applied Climatology 103(3-4): 441-450. http://doi.org/10.1007/s00704-010-0310-y

[9] Krüger E, Emmanuel R. (2013). Accounting for atmospheric stability conditions in urban heat island studies: The case of Glasgow, UK. Landscape \& Urban Planning 117(3): 112-121. http://doi.org/10.1016/j.landurbplan.2013.04.019

[10] Magli S, Lodi C, Contini FM, Muscio A, Tartarini P. (2016). Dynamic analysis of the heat released by tertiary buildings and the effects of urban heat island mitigation strategies. Energy \& Buildings 114(1): 164-172. http://doi.org/10.1016/j.enbuild.2015.05.037

[11] Mao W, Wang X, Cai J, Zhu M. (2016). Multidimensional histogram-based information capacity analysis of urban heat island effect using Landsat 8 data. Remote Sensing Letters 7(10): 925-934. http://doi.org/10.1080/2150704X.2016.1182656

[12] Vardoulakis E, Karamanis D, Fotiadi A, Mihalakakou G. (2013). The urban heat island effect in a small Mediterranean city of high summer temperatures and cooling energy demands. Solar Energy 94(4): 128-144. http://doi.org/10.1016/j.solener.2013.04.016

[13] Li CF, Shen D, Dong JS, Yin JY, Zhao JJ, Xue D. (2014). Monitoring of urban heat island in shanghai, china, from 1981 to 2010 with satellite data. Arabian Journal of Geosciences $\quad 7(10)$ : 3961-3971. http://doi.org/10.1007/s12517-013-1053-8

[14] Balcerak E. (2014). Statistical analysis describes urban heat island effect in Europe. Eos Transactions American $\begin{array}{lll}\text { Geophysical } & \text { Union }\end{array}$ http://doi.org/10.1002/2014EO060010

[15] Xu S. (2009). An approach to analyzing the intensity of the daytime surface urban heat island effect at a local scale. Environmental Monitoring \& Assessment 151(14): 289-300. http://doi.org/10.1007/s10661-008-0270-1

[16] Ramamurthy P, Bou-Zeid E. (2017). Heatwaves and urban heat islands: a comparative analysis of multiple cities. Journal of Geophysical Research Atmospheres 122(1): 168-178. http://doi.org/10.1002/2016JD025357

[17] Kang HQ, Zhu B, Zhu T, Sun JL, Ou JJ. (2014). Impact of megacity shanghai on the urban heat-island effects over the downstream city Kunshan. Boundary-Layer Meteorology 152(3): 411-426. http://doi.org/10.1007/s10546-014-9927-1 